\title{
Design têxtil como ferramenta de ressignificação para tecidos antimicrobianos pós-COVID-19.
}

Sarah de Godoy é mestranda em design pela Universidade Anhembi Morumbi com foco em nanotecnologia e suas aplicações no design de moda no Brasil. Pós-graduada (Lato Sensu) em gestão de marketing pelo Centro Universitário Senac de São Paulo/SP; Graduada em desenho de moda pela Faculdade Santa Marcelina - FASM/ SP. Membro do grupo de pesquisa no CNPq: Pós-digital no design e na arte, da Universidade Anhembi Morumbi, sob orientação do Prof. Dr. Milton Terumitsu Sogabe.

sarahdegodoy@gmail.com

ORCID 000-003-1143-2581

Milton Sogabe é graduado em Artes Plásticas, na FAAP-SP, mestrado e doutorado em Comunicação e Semiótica, na PUC-SP e pós-doutorado na Universidade de Aveiro, em Portugal. Docente aposentado do Instituto de Artes, da UNESP e desde 2017, docente do PPG Design da Universidade Anhembi Morumbi. Bolsista Produtividade do $\mathrm{CNPq}$ desde 2008.

milton.sogabe@anhembi.br ORCID 0000-0003-1286-9013
Resumo Este artigo analisa o aprimoramento dos aspectos funcionais, estéticos e ergonômicos no design de têxteis para vestuário com o uso da nanotecnologia. Para tanto, são articulados os fenômenos que geram ressignificações para o design de têxteis destinados à confecção de artigos para vestuário considerando o mundo pós-COVID-19. 0 método utilizado é o de estudo qualitativo e bibliográfico associado a questões filosóficas do design, partindo de reflexões conceituais sobre o universo do design e quais os diálogos deste campo com a produção de tecidos antimicrobianos para vestuário no mundo pós-COVID-19.

Palavras chave Nanotecnologia; Design têxtil; COVID-19; Antimicrobiano. 
Textile design as a resignification tool for post-COVID-19 antimicrobial tissues.

Abstract This article analyzes the improvement of functional, aesthetic and ergonomic aspects in the design of clothing textiles with the use of nanotechnology. To this end, we consider the phenomena that generate resignifications for the design of textiles for the manufacture of articles for clothing, considering the world after COVID-19. We User a qualitative and bibliographic method, associated with philosophical questions of design, based on conceptual reflections on the universe of design and what are the dialogues in this field with the production of antimicrobial fabrics for clothing in the post-COVID-19 world.

Keywords Nanotechnology, Textile Design, COVID-19, Antimicrobial

Diseño textil como herramienta de resignificación de tejidos antimicrobianos pos-COVID-19.

Resumen Este artículo analiza la mejora de los aspectos funcionales, estéticos y ergonómicos em el diseño de textiles de confección con el uso de la nanotecnología. Para ello, se consideran los fenómenos que generan resignificaciones para el diseño de textiles para la fabricación de artículos de confección, considerando el mundo posCOVID-19.

El método utilizado es el de un estudio cualitativo e bibliográfico asociado a cuestiones filosóficas del diseño, a partir de reflexiones conceptuales sobre el universo del diseño y cuáles son los diálogos en este campo con la producción de tejidos antimicrobianos para confección en el mundo post-COVID-19.

Palabras clave Nanotecnologia, diseño textil, COVID-19, antimicrobiano. 


\section{Introdução}

O presente artigo tem como objetivo analisar o aprimoramento dos aspectos funcionais, estéticos e ergonômicos no design de têxteis para vestuário com o uso da nanotecnologia, apresentando ressignificações para o design têxtil no mundo pós-COVID-19. O método utilizado é o de estudo qualitativo bibliográfico associado a questões filosóficas do design, a partir de reflexões conceituais sobre o universo do design e quais os diálogos deste campo com a produção de tecidos antimicrobianos para vestuário no mundo pós-COVID-19.

A escolha deste tema se dá pelas transformações da sociedade em função da pandemia pelo COVID-19, que gerou a necessidade de adequação dos hábitos de higiene, comportamento em espaços coletivos e artefatos de vestuário, que tem a função de atuar como barreira protetora e anti disseminadora de micróbios, despertando o questionamento sobre o significado do design têxtil neste processo, considerando que a nanotecnologia se apresenta como um recurso para o aprimoramento de produtos, porque seu desenvolvimento científico e sua manipulação tecnológica modificam e reinventam materiais e processos, permitindo que estruturas possam ser trabalhadas em níveis moleculares e atômicos, podendo organizarem-se e realinharem-se em resposta a estímulos externos (JORDÃO, 2009; BERGMANN; MAGALHÃES, 2017). Compreendemos a nanotecnologia como correspondendo à investigação e ao desenvolvimento tecnológico em nível atômico, molecular ou macromolecular, utilizando uma escala de comprimento de um a cem nanômetros $(1 \mathrm{~nm}=0,000000001 \mathrm{~m})$; a criação e a utilização de estruturas, dispositivos e sistemas que têm novas propriedades e funções por causa de seu tamanho reduzido; e a capacidade de controlar ou manipular a matéria em escala atômica (ENVIROMENTAL PROTECTION AGENCY, 2007). Nota-se que não se trata de uma tecnologia única, mas um agrupamento multidisciplinar de física, química, engenharia biológica, materiais, aplicações e conceitos em que tamanho é a definição característica (SHULTE; SALAMANCA-BUENTELLO, 2007).

No design têxtil, a possibilidade de incorporação de nanotecnologia nas fases de fiação, beneficiamento ou produção do artigo final, resultou no aprimoramento dos aspectos funcionais, estéticos e ergonômicos do design de têxteis para vestuário (PEZZOLO, 2013). 0 design de têxteis destinados a confecção de artigos para vestuário considera o tecido no seu todo, isto é, como um objeto tridimensional em que ambos os lados (direito e avesso) são indissociáveis das propriedades e características do todo (MELO, 1981). Neste cenário, o pensamento projetual para o desenvolvimento de têxteis nanotecnológicos tem caráter sistêmico, uma que vez que funcionalidade, ergonomia e estética estão integrados e são interdependentes para que o objetivo final da proposta seja alcançado (BERTALANFFY, 1972).

Segundo Johnson e Cohen (2010), nanotecnologia implementada no design têxtil foi projetada para atender necessidades específicas dos usuários, proporcionando novas propriedades funcionais, estéticas e ergonômi- 
cas aos tecidos destinados à confecção de artigos para vestuário, tais como: controle de temperatura, retardo de chamas, proteções ultravioleta e antimicrobiana, repelente de elementos como água, óleo, odor e insetos. Ainda segundo os autores, estes tecidos também apresentam um aprimoramento na sua performance no que diz respeito a conforto, qualidade, desempenho, acabamento, resistência e estabilidade.

Em 2020, com a pandemia gerada pelo COVID-19, os tecidos estão sendo empregados como barreira mecânica protetora e anti disseminadora de micróbios, principalmente na confecção de máscaras (ANVISA). Com o aprimoramento dos aspectos funcionais, ergonômicos e estéticos por meio da incorporação da nanotecnologia ao design de têxteis destinados a confecção de artigos para vestuário, é possível ampliar o espectro de finalidades do vestir no mundo pós-COVID-19, uma vez que os tecidos conseguem funcionar não só como barreira mecânica protetora, mas química também, atuando como uma segunda pele que pode ser multifuncional, confortável e estilosa ao mesmo tempo (MARTINS, 2008).

Neste contexto, a nanotecnologia expande o design para outro patamar, do ponto de vista da materialidade e do significado (LATOUR, 2014). Em relação a materialidade, no design têxtil, a nanotecnologia consiste na redução do tamanho de materiais que deverão ser manipulados e/ou estruturados para serem incorporados ao tecido (SENAI-SP, 2013; MEDEIROS; PATERNO; MATTOSO, 2006). No eixo da significação, a nanotecnologia atua, no design têxtil, como inovação incremental, o que resulta em produtos com novos significados (NORMAN, 2018).

Para melhor entendimento deste artigo, sua organização se dá em dois macromomentos, sendo o primeiro a análise dos aprimoramentos funcionais, estéticos e ergonômicos no design de têxteis para vestuário com o uso da nanotecnologia, a partir dos quais são apresentadas ressignificações para o design têxtil, considerando o mundo pós-COVID-19. E o segundo, o estudo qualitativo bibliográfico associado às questões filosóficas do design, onde o design têxtil é apresentado como ferramenta de ressignificação para a produção de tecidos antimicrobianos para vestuário no mundo pós-COVID-19.

\section{Análise dos aprimoramentos funcionais, estéticos e ergonômicos no design de têxteis para vestuário com 0 uso da nanotecnologia}

No design de têxteis para vestuário, os aspectos funcionais compreendem as relações entre um produto e seus usuários no nível orgânico-corporal, preenchendo as condições fundamentais para a sobrevivência do ser humano e mantendo a sua saúde física (LÖBACH, 2001). Em relação a aparência dos têxteis, Löbach (2001) afirma que esta é identificada pelo processo da percepção, atuando sobre a nossa psique, sendo importante que a aparência dos têxteis seja otimizada de acordo com as característi- 
cas perceptivas do ser humano, de tal forma que o usuário possa assimilá-las psiquicamente. $\mathrm{O}$ uso sensorial de têxteis destinados à confecção de artigos para vestuário (percepção destes têxteis com os sentidos, principalmente o visual, tátil e sonoro) se dá por meio dos aspectos estéticos do mesmo (ibidem).

De acordo com Löbach (2001, p.59 e 60), os aspectos estéticos são responsáveis pela "relação entre um produto e um usuário no nível dos processos sensoriais", sendo "a função estética dos produtos um aspecto psicológico da percepção sensorial durante o seu uso". Ainda de acordo com o autor, configurar produtos significa dotá-los de funções estéticas, atendendo à percepção multissensorial do usuário, que depende de dois fatores essenciais: das experiências anteriores com as características estéticas (forma, cor, superfície) e, da percepção consciente dessas características. Os aspectos estéticos se impõem à nossa percepção, unindo-se a outras funções e as superando, além de promover a sensação de bem-estar, identificando o usuário com o produto, durante o processo de uso (ibidem). A estética das questões é uma forma de iluminar os objetos, de enquadrá-los, de apresentá-los, de situá-los, em relação ao olhar dos observadores (LATOUR, 2014).

Os aspectos ergonômicos focam nas interações do ser humano com os artefatos, a partir de uma perspectiva unificada da ciência, engenharia, design, tecnologia e gerenciamento da compatibilidade humano-sistema, incluindo uma variedade de produtos, processos e ambientes naturais e artificiais, onde são buscados otimização e bem-estar do ser humano e um melhor desempenho de todo o sistema, o que contribui para a redução de riscos de mal funcionamento do produto, melhoria da usabilidade e redução de custos no ciclo de vida do produto (KARWOWSKI, 2005). Os aspectos ergonômicos melhoram algumas características do produto tais como a facilidade do uso, habilidade de aprendizagem, eficiência, conforto, segurança, adaptabilidade e satisfação do usuário (KARWOWSKI; SOARES E STANTON, 2011).

Dentro deste contexto, os mecanismos de ressignificação da nanotecnologia, por meio dos aspectos funcionais, ergonômicos e estéticos, para o design de têxteis para vestuário, no eixo da materialidade, consistem em manipulações de materiais em escala nanométrica, que afetam a estrutura e geram novas propriedades e características diferentes das originais (DURAN, MATTOSO \& MORAIS, 2006). Para a categorização de um produto ou processo trabalhado em nanoescala, isto é, em escala com grandezas de nanômetro, ou seja, da ordem dos bilionésimos do metro, adotou-se a definição desenvolvida pelo ISO TC 229 (International Organization for Standardization), em que se verificam duas características fundamentais: a) produtos ou processos tipicamente, mas não exclusivamente, abaixo de 100nm (cem nanômetros); b) propriedades físico-químicas diferentes dos produtos ou processos em escalas maiores. Um nanômetro equivale a um milionésimo de milímetro, medida tão pequena que 
são necessários cerca de 400.000 átomos amontoados para atingir a espessura de um fio de cabelo (MILLER, 2005).

Em relação à significação, no design têxtil, a nanotecnologia se apresenta como inovação incremental, por sua capacidade de reconfigurar têxteis utilizando o mesmo mecanismo fabril para a produção da nova proposta (GARCIA; CALANTONE, 2002; SCHERER; CARLOMAGNO, 2009). Segundo Norman (2008); Norman e Verganti (2014); Fialkowski (2016) e Kistmann (2016), esta inovação é definida a partir dos eixos da tecnologia e do significado, sendo o eixo da tecnologia definido pela capacidade de promover a adequação de produtos gerando novas soluções e o eixo da significação relacionado à capacidade da inovação incremental poder resultar em produtos com novos significados.

Dando continuidade a esse raciocínio e considerando o mundo pós-COVID-19, podemos destacar como inovação incremental no design de têxteis destinados à confecção de artigos para vestuário, a nanotecnologia antimicrobiana, que têm como principal função a inativação ou inibição de microrganismos que possam vir a provocar descoloração dos tecidos, odores desagradáveis ou até mesmo infecções (SUN; WORLEY, 2005 apud CORADI, 2018). Nesse sentido, dependendo de sua função, os têxteis antimicrobianos podem ser classificados em duas categorias: materiais biocidas ou biostáticos (ibidem).

A função biostática refere-se à inibição do crescimento dos microrganismos em têxteis, prevenindo a biodegradação do material e, por definição, envolve somente a proteção do material têxtil (SUN; WORLEY, 2005 apud CORADI, 2018). Já os materiais biocidas são capazes de inativar os microrganismos, esterilizando o material e possivelmente protegendo o usuário de ataques biológicos (ibidem). Neste contexto, o conhecimento do modo de atuação de um composto antimicrobiano é fator crucial para sua aplicação no material têxtil devido as possibilidades químicas e físicas para a produção de têxteis antimicrobianos, mas, a sua aplicação depende do agente ativo e do tipo de fibra em que vai ser incorporado (MICHIELSEN, et al., 2004; GAO E CRANSTON, 2008; SHAHIDI E WIENER, 2012 apud MAGALHÃES, 2015). Considerando essa abordagem, é relevante indicar, que nanotecnologia projetada para esse fim, já vem sendo utilizada em outros produtos também, como máquinas de lavar roupa, fabricando a cuba com polipropileno e prata tendo um efeito bactericida, assim como em colchões, com uso de resina com nanopartícula na fabricação de fios e fibras. (VASCONCELOS, 2007)

\section{Design têxtil como ferramenta de ressignificação para a produção de tecidos antimicrobianos para vestuário no mundo pós-COVID-19}

Para o mundo pós-COVID-19, o design têxtil como ferramenta de ressignificação proporciona novo sentido para a produção de tecidos antimicrobianos por meio da alteração de seu conceito, da sua percepção ou da 
sua interpretação original, tornando-o coerente para o usuário, sob novo ponto de vista, transformando-o para o contexto vigente (CARDOSO, 2013). Neste sentido, quando analisamos o design de algum artefato, estamos inquestionavelmente lidando com significados - sejam eles comerciais, simbólicos ou de outra ordem (LATOUR, 2014, p. 6).

Dando continuidade a essa abordagem, a possibilidade de contaminação e propagação de infeções foi o que consciencializou, a princípio, a indústria para a produção de nanotecnologia antimicrobiana para ser incorporada ao design têxtil com a finalidade de atender nichos específicos, como o de artigos têxteis hospitalares e esportivos GUTAROWSKA E MICHALSKI 2012; PERERA et al. 2013; apud MAGALHÃES, 2015).

Nanotecnologia antimicrobiana incorporada ao design têxtil deve apresentar baixa toxicidade para os usuários, ser eficiente contra um amplo espectro de microrganismos e eliminar seletivamente os microrganismos indesejados, cumprindo ainda a legislação, por meio da realização de testes de citotoxicidade antes de ser comercializada e ter um efeito durável aos processos de lavagem, secagem e engomagem, sendo este o maior desafio para a indústria (GAO; CRANSTON, 2008; YE et al., 2006 apud MAGALHÃES, 2015).

Outros critérios para a seleção da nanotecnologia antimicrobiana são: baixo custo, não produção de substâncias nocivas para o meio ambiente, manutenção da aparência e qualidade do têxtil e compatibilidade com o processamento têxtil habitual (GAO E CRANSTON 2008; RISTIC et al. 2011 apud MAGALHÃES, 2015). Por fim, os acabamentos antimicrobianos não devem eliminar a flora comensal da pele, uma vez que os microrganismos existentes na pele reduzem o $\mathrm{pH}$, criando um ambiente desfavorável para microrganismos patogênicos, fazendo com que sua eliminação possa ser prejudicial para o usuário (ELSNER 2006; Ye et al. 2006 apud MAGALHÃES, 2015).

Neste cenário, Ariyatum et al. (2005), constatam a importância do design de têxteis antimicrobianos destinados à confecção de artigos para vestuário estar direcionado ao usuário pelo seu condicionamento de uso. Essa pesquisa, direciona que, sobre a aplicação de artigos funcionais no mercado de massas, os usuários estão mais interessados neste tipo de produto, quando está relacionado com a saúde e com as aplicações que se adequam aos estilos de vida. A aceitação social também é um fator determinante e a definição do mercado-alvo é fundamental para o êxito do produto (ARIYATUM et al., 2005). Dentro desta linha de pensamento, Bruno et al. (2008) descreve que "as inovações serão empurradas por tecnologias-chave e puxadas pelo consumo-consciente". É como se a materialidade e a moralidade finalmente se unissem (LATOUR, 2014).

No que diz respeito ao vestuário Taieb et al. (2010, p. 86) definem as funcionalidades que podem ser aplicadas ao vestuário como sendo "essenciais para a produção de valor acrescentado aos têxteis", ressaltando que os "usuários estão exigindo produtos têxteis com maior performance". Desta forma, a produção de têxteis destinados a confecção de artigos para 
vestuário, que possuem nanotecnologia antimicrobiana, implicará um novo pensamento sobre design têxtil e ciência para inovar em soluções, considerando que a possível democratização dos têxteis antimicrobianos destinados à confecção de artigos para vestuário, no mundo pós-COVID-19, reside no potencial do processo de aplicação da nanotecnologia antimicrobiana em fibras e tecidos, para que a concepção das necessidades do usuário seja atendida, de forma que a proposta final resulte em um novo produto com uma nova funcionalidade ou com um upgrade, que potencialize as funcionalidades originais (BAURLEY, 2003; TAIEB et al 2010).

Neste viés, o design têxtil se apresenta como um processo de configuração de tecidos, que visa ampliar seus aspectos funcionais, comerciais, tornando-os mais usáveis, mais agradáveis ao usuário, mais aceitáveis, mais sustentáveis, dependendo das diversas restrições com as quais o projeto precisa lidar (LATOUR, 2014). A expansão do conceito de design têxtil no mundo pós-COVID-19, indica uma mudança profunda em nossa constituição emocional: no momento em que a noção do que significa "fazer", no caso, têxteis antimicrobianos, também está sofrendo profundas modificações, as quais resultam no pensamento de que as coisas já não são "feitas" ou "fabricadas", mas sim cuidadosamente - ou cautelosamente - elaboradas através do design (ibidem). Nesse sentido é extremamente importante atentarmos para o quão profundamente encaramos os artefatos cotidianos, elementos constituídos pelas diversas facetas do design (ibidem).

\section{Considerações finais}

O estudo direcionou o design têxtil como ferramenta de ressignificação, a partir de reflexões conceituais sobre o universo do design e seus diálogos com a produção de tecidos antimicrobianos para vestuário no mundo pós-COVID-19. Ficou constatado que a produção de têxteis antimicrobianos teve como ponto de partida a conscientização da indústria acerca das possibilidades de contaminação e propagação de infeções nos nichos de artigos têxteis hospitalares e esportivos, sendo estes os primeiros a se beneficiarem com a proposta.

A análise dos aprimoramentos funcionais, estéticos e ergonômicos no design de têxteis para vestuário por meio da atuação da nanotecnologia como inovação incremental aponta que, o desenvolvimento de têxteis nanotecnológicos, em especial, os antimicrobianos, partem de demandas mercadológicas e tem como eixo questões de funcionalidade. Contudo, a nanotecnologia antimicrobiana no design têxtil integra os aspectos ergonômicos e estéticos às questões de funcionalidade, a fim de promover conforto, bem-estar e estilo aos usuários, suprindo as necessidades técnicas e simbólicas atreladas aos tecidos, que antes não tinham essa propriedade.

A democratização dos têxteis antimicrobianos no mundo pós-COVID-19 poderá inaugurar uma nova fase da função das roupas para os usu- 
ários, atuando como uma segunda pele tecnológica, que transcenderá as necessidades e funções atuais, para as quais é empregada. Dentro deste contexto, a aplicabilidade da nanotecnologia antimicrobiana no design têxtil, poderá abranger todos os nichos e segmentos de mercado, atuando de maneira profilática e protetora de seus usuários.

\section{Referências}

AGÊNCIA NACIONAL DE VIGIL NCIA SANITÁRIA-ANVISA. Covid-19: tudo sobre máscaras faciais de proteção. 2020. Disponível em: http://portal.anvisa.gov.br/noticias/-/ asset_publisher/FXrpx9qY7FbU/content/covid-19-tudo-sobremascaras-faciais-de-protecao/219201. Acesso em: 05 jul. 2020.

ARIYATUM, B., HOLLAND, R., HARRISON, D., KAZI, T., 2005. The future design direction of smart clothing development. J. Text. Inst. 96, 199-210.

BAURLEY, $S$ et al. Communication-Wear: user feedback as part of a co-design process. Lecture Notes in Computer Science, v. 4813, 2007.

BERGER, Peter. L.; LUCKMANN, Thomas. A construção social da realidade: um livro sobre sociologia do conhecimento. Lisboa: Dinalivro, 2004.

BERGMANN, M., \& MAGALHÃES, C. (2017). Hybrid materials: Textile nature in transformation. DAT Journal, 2(2). https://doi.org/10.29147/2526-1789.DAT.2017v2i2p144-158

BERTALANFFY, Ludwig von. Teoria Geral dos Sistemas. Petrópolis: Vozes, 1972.

BRUNO, Flavio da Silveira et al. Estudo Prospectivo Setorial Têxtil e Confecção. Relatório técnico. Centro de Gestão e Estudos Estratégicos. 2008.

CARDOSO, Rafael. Design para um Mundo Complexo. São Paulo: Cosac Naify, 2016.

CASTRO, E.M. de Melo e. Introdução ao Desenho Têxtil. Lisboa: Editorial Presença, 1981.

CORADI, Michaela. Têxteis antimicrobianos produzidos pela modificação superficial de tecidos de algodão e imobilização de enzima pectinolítica. São Paulo, 2018.

Covid-19: tudo sobre máscaras faciais de proteção. 2020. Disponível em: http://portal. anvisa.gov.br/noticias/-/asset_publisher/FXrpx9qY7FbU/content/covid-19-tudo-sobre-mascaras-faciais-de-protecao/219201. Acesso em: 05 jul. 2020.

ELSNER P. Antimicrobials and the skin physiological and pathological flora. Curr Probl Dermatol, 2006.

ENVIRONMENTAL PROTECTION AGENCY (EPA). Nanotechnology white paper. Prepared for the US EPA by members of the Nanotechnology Workgroup, a group of EPA's Sciencie Policy Council. Washington, 2007.

FIALKOWSKI, V. P.; KISTMANN, V. B. 2016. Gestão de Design e Inovação Incremental: Adequação de Plataformas de Produtos Pré-existentes em um Novo Mercado. E-Revista LOGO, v. 5, n. 2, 2016. 
GARCIA, R; CANTALONE, R. A critical look at technological innovation typology and innovativeness terminology: a literature review. The Journal of Product Management, v. 19, 2002. INTERNATIONAL ORGANIZATION FOR STANDARDIZATION (ISO). Ballot on ISO/DTR 12885: nanotechnologies: health and safety practices in occupational settings. Geneva, 2017. Documento em PDF: norma não publicada em discussão pública.

JOHNSON, Ingrid. COHEN, Allen C. Fabric Science. New York, NY: Fairchild Publications, v. 9, 2010.

JORDÃO, Fabio. O que é nanotecnologia? Tecmundo. 2009.

KARWOWSKI, W. Ergonomics and human factors: the paradigms for science, engineering, design, technology, and management of human. Compatible systems. Ergonomics, v. 48, n. 5, 2005.

KARWOWSKI, W.; SOARES, M.M. e STANTON, N. (2011). Handbook of Human Factors in Consumer Product Design. Vol. 1: Methods and Techniques Vol. 2: Uses and Applications. Boca Raton, CRC Press.

LATOUR, Bruno. Um Prometeu Cauteloso? Alguns passos rumo a uma filosofia do design (com especial atenção a Peter Slotedijk). Agitprop: revista brasileira de design, São Paulo, v.6, n. 58, jul/ago. 2014.

LÖBACH, Bernd. Design Industrial: Bases para a Configuração de Produtos Industriais Editora Edgard Blücher Ltda, 2001.

MAgAlHÃES, Andréia Patrícia Souza Alves. Atividade antimicrobiana em têxteis. Portugal, 2015.

MARTINS, S. B. Ergonomia e moda: repensando a segunda pele. In: PIRES, D.B. Design de Moda: olhares diversos. Barueri: Editora Estação das Letras e Cores, 2008.

MEDEIROS, Eliton S.; PATERNO, Leonardo G.; MATTOSO, Luiz H. C. Nanotecnologia. In: DURÁN, Nelson; MATTOSO, Luiz Henrique Capparelli; MORAIS, Paulo Cezar de. Nanotecnologia: Introdução, preparação e caracterização de nanomateriais e exemplos de aplicação. São Paulo: Artliber, 2006.

MERLEAU-PONTY, Maurice. Fenomenologia da Percepção. Editora Martins Fontes,1999.

MILLER, JOHN C., SERRATO, R., KUNDAHL, G., “The Handbook of Nanotechnology: Business, Policy and Intellectual Property Law". First Edition, New Jersey, Wiley, 2005.

NORMAN, Donald A. Design emocional: por que adoramos (ou detestamos) os objetos do dia-a-dia. Rio de Janeiro: Rocco, 2008.

NORMAN, D.; VERGANTI, R. Incremental and radical innovation: design research versus technology and meaning change. Design Issues, v. 30, n. 1.

PEZZOLO, Dinah Bueno. Tecidos: história, trama, tipos e uso. São Paulo: SENAC / São Paulo, 2007.

SENAI-SP. Nanomundo: um universo de descobertas e possibilidades. São Paulo: SENAI-SP, 2013. 
Design têxtil como ferramenta de ressignificação para tecidos antimicrobianos pós-COVID-19 19

SCHERER, F. O. ; CARLOMAGNO, M. S. Gestão da Inovação na prática: como aplicar conceitos e ferramentas para alavancar a Inovação. São Paulo: Atlas, 2009.

SHULTE, Paul A.; SALAMANCA-BUENTELLO, Fabio. Ethical and scientific issues of nanotechnology in the workplace. Ciência Saúde Coletiva, Rio de Janeiro, v. 12, n. 5, sep./ oct. 2007.

SOLOMON, M. Consumer Behavior: Buying, Having, and Being. New Jersey, Upper Saddle. 2009.

TAIEB, A. H.; MSAHLI, S; SAKLI, F. Modelling consumer satisfaction degree of functional textile. Journal of Modelling and simulation of Systems. V. 1, n. 2, 2010.

VASCONCELOS, Yuri. Múltiplas utilidades- Resinas nanoestruturadas funcionam como bactericidas e fungicidas em máquinas de lavar roupa e colchões. In Revista Pesquisa FAPESP, junho de 2007. Pág. 72-75. Disponível em https://revistapesquisa.fapesp.br/multiplas-utilidades/ Acesso em 19/04/2021 